\title{
Investigation of three level code division multiplexing performance over high speed optical fiber communication system
}

\begin{abstract}
In this research, performance of Three Level Code Division Multiplexing (3LCDM) technique is investigated for high-speed optical fiber communication systems. It is shown that $40 \mathrm{~Gb} / \mathrm{s}(2 \times 20 \mathrm{~Gb} / \mathrm{s}) 3 \mathrm{LCDM}$ system perform s better than the conventional $40 \mathrm{~Gb} / \mathrm{s}$ non return to zero (NRZ-OOK) in term the dispersion tolerance. At $40 \mathrm{~Gb} / \mathrm{s}$, the lower level displays a nearly analogous behaviour of positive and negative chromatic dispersions tolerance which stands about $\pm 98 \mathrm{ps} / \mathrm{nm}$ while the upper level has chromatic dispersion tolerance of $\pm 81 \mathrm{ps} / \mathrm{nm}$ at BER of $10-9$. These values are higher than that of $40 \mathrm{~Gb} / \mathrm{s}$ conventional NRZ, which is approximately $\pm 49 \mathrm{ps} / \mathrm{nm}$.
\end{abstract}

Keyword: Optical communication; 3LCDM; Chromatic dispersion 